Pesq. Vet. Bras. 30(11):996-1002, novembro 2010

\title{
Histomorfometria das meninges encefálicas de ratos Wistar em diferentes faixas etárias ${ }^{1}$
}

\author{
Kleber F. Pereira ${ }^{2 *}$, Vanessa M. Lima ${ }^{3}$, Celso I. Conegero ${ }^{4}$ \\ e Renato P. Chopard ${ }^{5}$
}

\begin{abstract}
Pereira K.F., Lima V.M., Conegero C.L. \& Chopard R.P. 2010. [Histomorphometry of encephalic meninges of Wistar rats in different bands.] Histomorfometria das meninges encefálicas de ratos Wistar em diferentes faixas etárias. Pesquisa Veterinária Brasileira 30(11):996-1002. Curso de Ciências Biológicas, Universidade Federal de Goiás, Unidade Jatobá, Setor Parque Industrial, Jataí, GO 75800-000, Brazil. E-mail: kpereira@usp.br

The development of the nervous system is very complex and there are few studies about the organization of the brain envoltories related to the encephalus growing. Using the rat as an animal model, it was proposed to evaluate the several structural aspects of paquimeninge and leptomeninge in different ages. It was used 4 groups of different ages and processed according to the techniques of the light and transmission microscopy. It was verified that the adult rats present a higher area of collagen fibers of type I and III, if compared to the others groups. It was found that, the collagen fibers of type III occupy, in all analyzed groups, a higher area when compared to type I fibers. The results reveal that the Weigert Oxona's staining, which shows elastics, elauninics, and oxitalanics fibers, showed a statistically difference when compared to the Weigert's staining and Verhoeff's staining that show elauninics and elastics fibers, respectively. The ultra-structural aspects demonstrated the presence of many fibroblasts and mitochondria in the paquimeninge and also in the leptomeninges of the neonats and adults groups, indicating the high cellular activity and consequently, an intense formation of conjunctive tissue. As collagen fibers of type III acting on the structural maintenance of delicate and expansive tissues, the study shows that the function of the encephalic meninges are not only related to the to resistance to tractions and tensions that the encephalus is subjected. But also the function related to the distensibility of the meningeos and brain vases according to the sanguineous apport in several specific functions of the nervous system.
\end{abstract}

INDEX TERMS: Encephalic meninges, collagen, elastic fibers, histomorphometry.

RESUMO.- O desenvolvimento do sistema nervoso é bastante complexo, existindo poucos estudos sobre a organização dos envoltórios cerebrais relacionados ao crescimento encefálico. Utilizando como modelo experimental o rato,

\footnotetext{
1 Recebido em 24 de fevereiro de 2009.

Aceito para publicação em 24 de agosto de 2010

2 Docente do Curso de Ciências Biológicas, Universidade Federal de Goiás (UFG), Campus Jataí, Unidade Jatobá, BR 364 Km 192, Setor Parque Industrial, Jataí, GO 75800-000, Brasil. *Autor para correspondência: kpereira@usp.br

${ }^{3}$ Acadêmica do Curso de Ciências Biológicas, UFG, Jataí, GO.

${ }^{4}$ Departamento de Ciências Morfofisiológicas, Universidade Estadual de Maringá (UEM), Av. Colombo 5790, Jd. Universitário, Maringá, PR 87020-900, Brasil.

${ }^{5}$ Instituto de Ciências Biomédicas, Universidade de São Paulo (USP), Av. Prof. Lineu Prestes 2415, São Paulo, SP 05508-900, Brasil.
}

analisaram-se os diferentes aspectos estruturais $\mathrm{e}$ morfométricos da paquimeninge e leptomeninge durante $o$ processo de envelhecimento. Foram utilizados quatro grupos de ratos em diferentes faixas etárias e analisadas as meninges em microscopias de luz e eletrônica. Verificamos que o grupo de ratos adultos apresentou uma maior área de fibras colágenas tanto do tipo I e quanto do tipo III, em relação aos outros grupos. Encontramos também que as fibras colágenas do tipo III em todos os grupos analisados ocupam uma maior área quando comparados com as fibras do tipo I. Os resultados revelam que a coloração de Weigert Oxona, que mostra fibras elásticas, elaunínicas e oxitalânicas, apresentou uma diferença estatisticamente maior de fibras quando comparados com as colorações de Weigert e Verhoeff, que mostra fíbras elaunínicas e elásti- 
cas, respectivamente. Os resultados ultra-estruturais demonstraram a presença de muitos fibroblastos e mitocôndrias tanto na paquimeninge como nas leptomeninges dos grupos de ratos neonatos e adultos, indicativo de alta atividade celular e conseqüentemente, intensa formação de tecido conjuntivo. Como as fibras colágenas do tipo III atuam na manutenção da estrutura de tecidos delicados e expansíveis, o estudo mostra que as funções das meninges encefálicas não estão relacionadas apenas com a resistência a trações e tensões a que estão sujeitas o encéfalo. Mas também a função relacionada com a distensibilidade dos vasos meníngeos e cerebrais de acordo com a necessidade do aporte sanguíneo em diversas funções específicas regionais do tecido nervoso.

TERMOS DE INDEXAÇÃO: Meninges encefálicas, fibras elásticas, fibras colágenas, histomorfometria.

\section{INTRODUÇÃO}

O encéfalo, assim como a medula espinal, está envolto por três meninges que são denominadas dura-máter (paquimeninge), pia-máter e aracnóide (ambas, em conjunto, são denominadas leptomeninge) e são fundamentais para a sustentação e proteção do Sistema Nervoso Central. A dura-máter é a membrana mais externa, resistente e espessa, abundante em fibras colágenas, apresentando fibras elásticas em algumas extensões, sendo grandemente vascularizada e inervada. A aracnóide é a membrana média, muito delgada, não possuindo vasos sanguíneos nem nervos em seu domínio. A pia-máter é a membrana mais interna e compõe-se de tecido reticular e fibras colágenas, penetrando entre os giros dos hemisférios cerebrais e entre as folhas do cerebelo, sendo amplamente vascularizada e inervada (Ham 1965, Greep 1966, Lesson \& Leeson 1966, Gray 1973).

Os componentes colágenos e elásticos apresentam alterações com o envelhecimento, assim como outros tecidos e órgãos do corpo humano (Robert 1995). As modificações morfoquantitativas do colágeno foram estudadas em vários órgãos, como músculos, fígado e pulmões, verificando-se que o envelhecer resulta em modificações dos diâmetros das fibrilas colágenas e na disposição, tipos e quantidade do colágeno (Schaub 1964), onde modificações na composição química e morfológica no sistema de fibras elásticas foram também constatadas. Na pele, o envelhecimento faz com que as fibras elásticas se tornem progressivamente tortuosas e com superfície irregular, as tortuosidades significariam que as fibras foram estiradas e a seguir perderam a elasticidade, determinando, como conseqüência, dobras ou rugas (Imayama \& Braverman 1989).

O desenvolvimento do sistema nervoso é bastante complexo, existindo poucos estudos sobre a organização dos envoltórios cerebrais relacionados ao crescimento do encéfalo. Utilizando como modelo experimental o rato, nos propomos a analisar os diferentes aspectos estruturais da paquimeninge e leptomeninge em diferentes faixas etárias, procurando verificar se existem ou não modificações des- de o nascimento até a velhice, objetivando os constituintes de resistência e tensão - os sistemas de fibras colágenas e elásticas.

\section{MATERIAL E MÉTODOS}

Foram utilizados 40 ratos albinos machos (Rattus norvegicus), linhagem Wistar, que foram divididos em quatro grupos de diferentes faixas etárias, sendo: Grupo A: 10 ratos neonatos de até 21 dias; Grupo B: 10 ratos jovens com 60 dias; Grupo C: 10 ratos adultos com 200 dias; Grupo D: 10 ratos velhos com 450 dias de idade, sendo que 5 ratos de cada grupo foram utilizados para microscopia de luz e 5 de cada grupo para microscopia eletrônica de transmissão.

Mediante aprovação do Comitê de Ética em Experimentação Animal, os ratos foram fornecidos pelo Biotério Central do Instituto de Ciências Biomédicas da Universidade de São Paulo e mantidos durante o experimento em gaiolas individuais no Biotério do Departamento de Anatomia do mesmo Instituto, em sala com temperatura controlada $\left(22 \pm 2^{\circ} \mathrm{C}\right)$ e regime de fotoperíodo de $12 \mathrm{~h}$ claro/12 h escuro. Os grupos receberam ração NUVILAB (recomendada por National Research Council \& National Institute of Health - USA) com nível de proteína (22\%) e água potável, ambos ad libitum.

Microscopia de luz. Os 5 ratos foram imobilizados e anestesiados com injeção intraperitonial de pentobarbital sodium (Hypnol, $40 \% \mathrm{mg} / \mathrm{kg}$ ). Para a coleta das meninges, foi realizado rebatimento dos tecidos de revestimento do crânio, seguido de abertura da calota craniana no sentido pósteroanterior, seguindo o plano sagital mediano, desde a altura ossos interparietais até a altura dos ossos nasais. Os ossos interparietais, parietais e frontais foram removidos sem lesionar a dura-máter, com osteótomo.

A região média do seio sagital superior, contendo as três meninges e a parte correspondente do encéfalo subjacente foi coletada, processada a rotina histológica e incluídas em parafina para realização de cortes histológicos de $5 \mathrm{~mm}$ e corados pelas técnicas de: Hematoxilina Férrica (Verhoeff, evidenciação de fibras elásticas); Resorcina Fucsina (Weigert, evidenciação de fibras elásticas e elaunínicas); Resorcina Fucsina após oxidação com solução aquosa a $1 \%$ de oxona (Weigert Oxona, evidenciação de fibras elásticas, elaunínicas e oxitalânicas); Azan (evidenciação do componente colágeno); Picrosírius (observação do componente colágeno); Hematoxilina e Eosina (evidenciação do componente celular); e Weigert Van-Gieson (evidenciação e disposição da estrutura elástica no interior do tecido colágeno).

Microscopia eletrônica de transmissão. Após prévia anestesia, a artéria aorta abdomial do rato foi bloqueada com pinça hemostática, e a artéria carótida comum foi perfundida com solução salina e glutaraldeído, fixando as meninges encefálicas dos animais. Foram coletadas amostras pequenas das meninges encefálicas com aproximadamente $1 \mathrm{~mm}^{3}$. As peças permaneceram por aproximadamente 2 horas no fixador de glutaraldeído a 2,5\%, realizando-se a seguir a pós-fixação em solução de tetróxido de ósmio a $2 \%$ por 2 horas a $4^{\circ} \mathrm{C}$ seguido de desidratação em série ascendente de álcoois e inclusão em uma mistura de resina e óxido de propileno na proporção 1:1. Cortes semifinos, de 1 a 3 micrômetros de espessura foram feitos em ultra-micrótomo (Leica UltraCut UCT, Reichert \& Jung, Germany), contrastados com acetato de uranila alcoólica (Watson 1958) e citrato de chumbo (Reynolds 1963) por 
três a quatro minutos, lavados em água destilada e observados em microscópio eletrônico de transmissão J.E.M.-1010 (Departamento de Histologia do Instituto de Ciências Biomédicas, Universidade de São Paulo).

Morfometria de fibras elásticas. O estudo histomorfométrico dos sistemas de fibras elásticas foi realizado através do cálculo da densidade linear (LD), que é mensurado em micrômetros quadrados. O comprimento estimado das fibras do sistema elástico foi realizado utilizando a fórmula básica $L$ $=2 \mathrm{Q} \times \mathrm{EV}$, onde $\mathrm{L}$ é o comprimento de fibras por unidades de volume; $\mathrm{Q}=$ número de intersecções de fibras elásticas numa secção plana; e EV é a unidade de volume. As secções histológicas das meninges foram observadas sob colorações de Hematoxilina Férrica, (evidenciação de fibras elásticas); Resorcina Fucsina (evidenciação de fibras elásticas e elaunínicas); Resorcina Fucsina após oxidação com solução aquosa a $1 \%$ de oxona (evidenciação de fibras elásticas, elaunínicas e oxitalânicas) e analisadas ao microscópio de luz com objetiva de 100x, em imersão, e ocular de compensação Kf 10x18, com gratículo de integração de 400 pontos, exibindo 20 retas paralelas. A distância (I) entre os pontos neste sistema é de $5 \mu \mathrm{m}$ e a distância (d) entre as linhas é de $4,94 \mu \mathrm{m}$. Para estimativa do erro de $5 \%$, cinco campos $(n=15)$ foram analisados usando-se o sistema-teste de 400 pontos.

Morfometria de fibras colágenas. $\mathrm{O}$ estudo do sistema de fibras colágenas foi realizado através da captura de campos aleatórios por meio do programa Image Pró-Plus 3.0 (Departamento de Ciências Morfofisiológicas da Universidade Estadual de Maringá), obtidas sob coloração de Picrosírius para obser- vação do componente colágeno. Foram feitos cortes transversais nas meninges encefálicas de ratos em diferentes faixas etárias e de cada lâmina foi capturado um total de cinco campos, nos quais foi quantificada a densidade de fibras colágenas do tipo I e do tipo III, sendo a área de cada campo equivalente a $42.291,79 \mathrm{~mm}^{2}$ (fibras analisadas sob luz polarizada).

Estatística. Com a finalidade de comparar a densidade linear dos componentes fibrosos elásticos e colágenos das meninges encefálicas entre as diferentes faixas etárias, aplicou-se análise de variância com dois fatores: faixa etária e coloração. A seguir empregaram-se comparações múltiplas pelo método de Tukey. $O$ nível de significância adotado para os dois testes foi de $5 \%$. A equação da regressão linear em cada uma das colorações foi de:

$$
\begin{aligned}
& \operatorname{LD}(\text { Weigert })=0,0006293+0,000407768 \times \text { Idade; } \\
& \text { LD (Verhoeff })=0,0006424+0,00044075 \times \text { Idade; } \\
& \operatorname{LD} \text { (Weigert Oxona })=0,0008442 .
\end{aligned}
$$

\section{RESULTADOS}

Em todos os grupos analisados, observou-se a presença da paquimeninge e leptomeninge. Próximo à região do seio sagital superior, as meninges encefálicas do grupo de ratos neonatos apresentaram-se estruturadas em três camadas distintas: na primeira, a paquimeninge; na segunda nota-se a presença de núcleos de fibroblastos continuando-se lateralmente em feixes conjuntivos com disposição predominantemente longitudinal entre paquimeninge e lep-

Fig.1. Corte histlógico frontal de $5 \mathrm{~mm}$ das meninges encefálicas na região do seio sagital superior. Hematoxilina-Eosina. (A) Grupo neonato, onde observamos as fibras colágenas na paquimeninge (dm) dispostas em camadas distintas, com feixes conjuntivos predominantemente longitudinais (asterisco) e núcleos de fibroblastos (seta) e presença da pia-máter (pm). 125x. (B) Grupo jovem, onde observamos regularidade dos feixes de fibras colágenas na paquimeninge (dm) e em sua margem inferior, um aglomerado de células sangüíneas (asterisco) com a presença de núcleos achatados de células endoteliais (seta), preenchendo as lacunas adjacentes ao seio sagital superior.
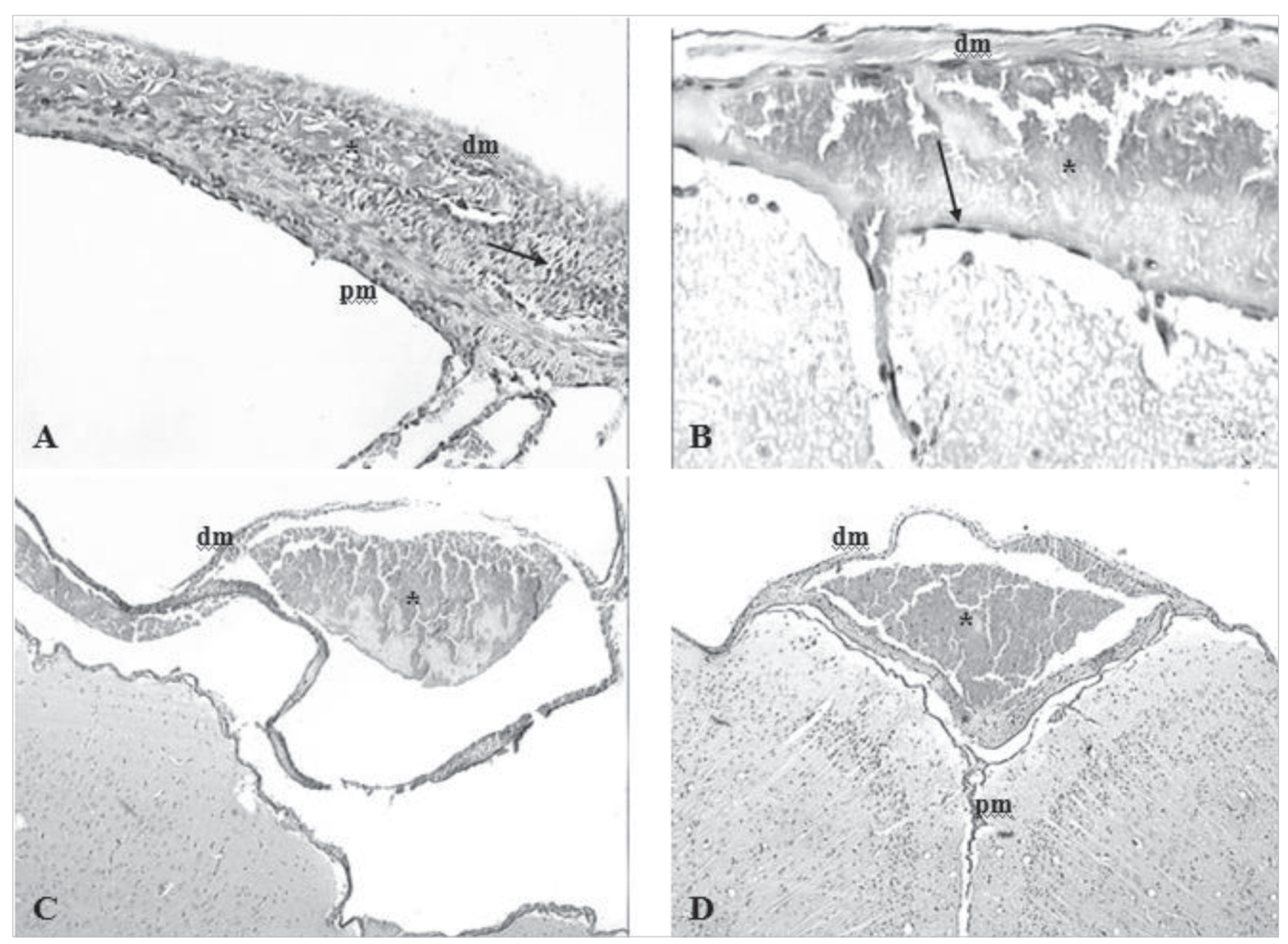

250x. (C) Grupo adulto, evidenciando a disposição dos feixes de fibras colágenas da paquimeninge (dm) e em sua margem inferior, um aglomerado de células sangüíneas (asterisco). 50x. (D) Grupo velho evidenciando a paquimeninge (dm) dirigindose lateralmente para a parte escamosa do osso temporal, um aglomerado de células sangüíneas no interior do seio sagital superior (asterisco) e a pia-máter ( $\mathrm{pm})$ penetrando-se inferiormente no interior dos hemisférios cerebrais. 50x. 
tomeninge, o que caracteriza uma paquimeninge em organização; e, na terceira, observou-se a presença da piamáter. Nos grupos de ratos jovens, adultos e velhos, a paquimeninge apresenta-se constituída por feixes conjuntivos organizados, caracterizando uma regularidade de seus componentes. Em sua margem interna, nota-se um aglomerado de células sangüíneas com a conseqüente presença de células endoteliais, com núcleos achatados dispostos numa única camada, preenchendo as lacunas adjacentes ao seio sagital superior (Fig.1). Em todos os grupos analisados, a pia-máter apresentou-se envolvendo 0 encéfalo, penetrando nos hemisférios e sulcos cerebrais.

Evidenciou-se que o componente colágeno do grupo de ratos neonatos, sob luz polarizada, apresenta-se constituído de colágeno do tipo III na paquimeninge e colágeno do tipo I na camada de paquimeninge em organização. A leptomeninge apresenta-se constituída de colágeno I e III. A paquimeninge do grupo de ratos jovens, adultos e veIhos apresentou-se constituída tanto de colágeno do tipo I quanto de III. No grupo de ratos jovens, o colágeno tipo III está presente em quase toda extensão da paquimeninge e notou-se a presença do colágeno tipo I na leptomeninge envolvida pelo colágeno tipo III. No grupo de ratos adultos, a paquimeninge apresenta-se em quase toda sua extensão constituída por colágeno do tipo III e em algumas regiões de colágeno do tipo I. O colágeno I pode também ser encontrado na leptomeninge tanto no grupo adulto como no do grupo velho. No grupo adulto a densidade de fibras encontradas foi maior do que os demais grupos analisados, tanto fibras colágenas do tipo I como do tipo III, sendo que, em todos os grupos, as fibras do tipo III apresen-

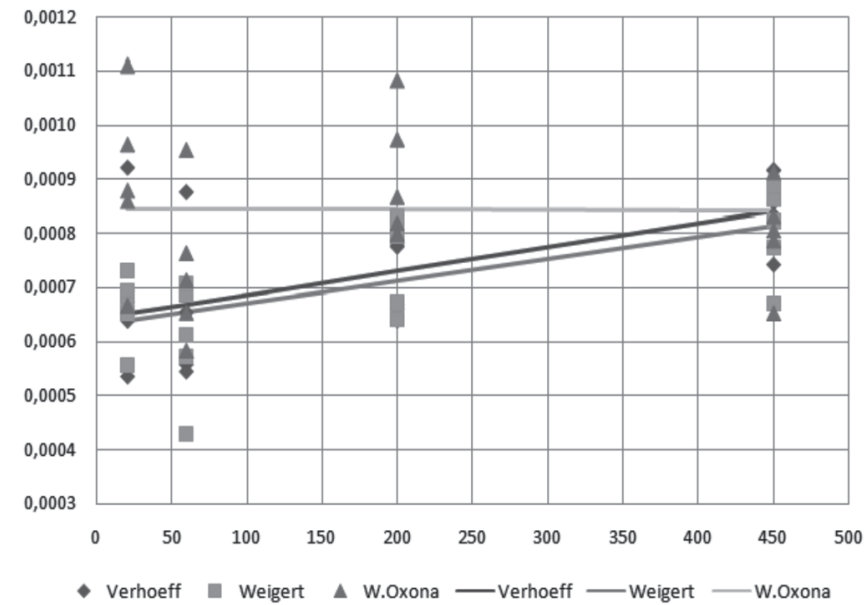

Fig.2. Regressão linear da densidade linear de fibras elásticas, elaunínicas e oxitalânicas nas meninges encefálicas de ratos neonatos, jovens, adultos e velhos em função da faixa etária.

\begin{tabular}{|c|c|c|}
\hline & Tipo I $(n=5)$ & Tipo III $(n=05)$ \\
\hline Neonato & $842,4 \pm 175,6$ & $1188,8 \pm 521,7$ \\
\hline Jovem & $758,5 \pm 401,7$ & $705,2 \pm 336,7$ \\
\hline Adulto & $1867,4 \pm 754,7$ & $3054,9 \pm 958,0$ \\
\hline Velho & $809,4 \pm 312,0$ & $1301,0 \pm 505,1$ \\
\hline
\end{tabular}

Fig.3. Corte histológico frontal de $5 \mathrm{~mm}$ das meninges encefálicas na região do seio sagital superior. (A) Grupo jovem, evidenciando a presença de fibras elásticas (setas) entremeadas ao tecido colágeno. Weigert Van-Gieson, 1250x. (B) Grupo velho, evidenciando a presença de fibras elásticas espessas e curtas (setas), sem distribuição uniforme no interior da meninge. Verhoeff, 1250x. (C) Grupo adulto, onde notamos a presença de fibras elásticas longas e finas (setas), sem distribuição uniforme no interior da meninge. Weigert, 1250x. (D) Grupo adulto, onde observamos a presença de tecido colágeno na paquimeninge (dm), se continuando no seio sagital superior (seta), e também na pia-máter (pm). Azan, 250x.

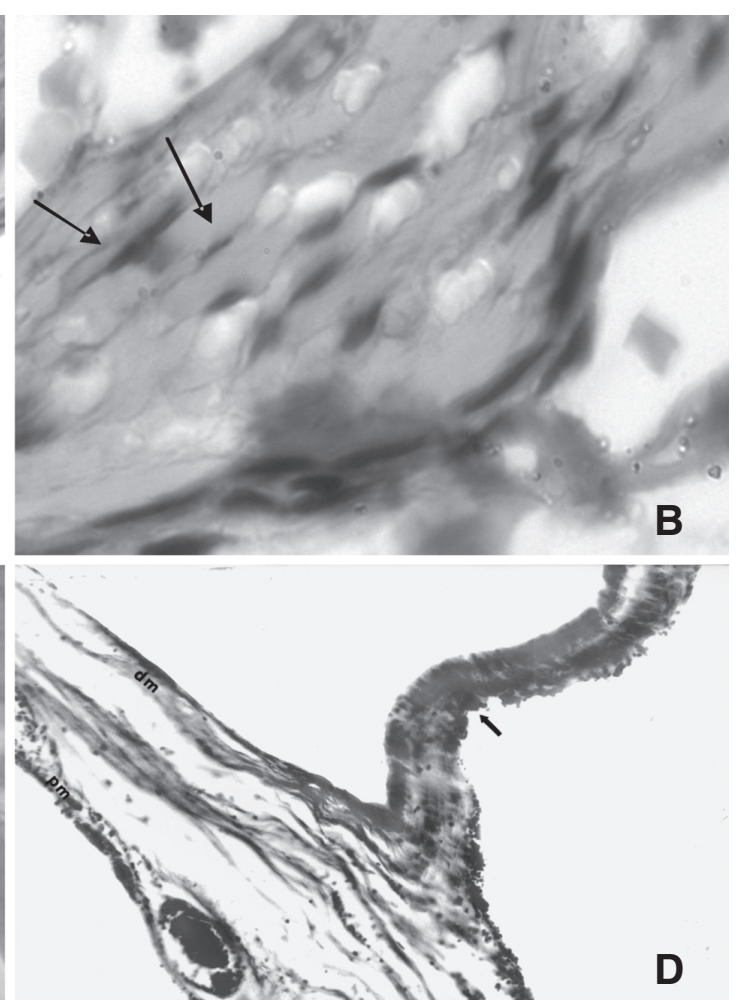


tam uma maior área quando comparada com as do tipo I (Fig.2, Quadro 1).

O componente elástico foi evidenciado nas meninges encefálicas entremeado com o componente colágeno em todos os grupos analisados. Fibras colágenas foram encontradas em toda extensão, tendo orientação longitudinal e seguindo o maior eixo da meninge. Diferentemente deste, as fibras elásticas maduras, elaunínicas e oxitalânicas não apresentam distribuição estrutural uniforme (Fig.3). A coloração de Weigert Oxona, que evidencia fibras elásticas, elaunínicas e oxitalânicas, apresentou uma diferença estatisticamente maior de fibras quando comparados com as colorações de Weigert, que evidencia fibras elásticas e elaunínicas e Verhoeff, que evidencia fibras elásticas, nos grupos de ratos neonatos, jovens e adultos. Ao analisar a quantidade de fibras elásticas nos diferentes grupos, verificamos que o grupo de ratos jovens apresentou uma diferença significativamente menor quando comparados com os grupos de ratos adultos e velhos. O grupo de ratos neonatos não apresentou diferença significativa quando comparado com os demais grupos.

$\mathrm{Na}$ análise de microscopia eletrônica de transmissão, as meninges encefálicas do grupo de ratos neonatos, apresentaram-se estruturadas em toda sua extensão por fibras colágenas. No grupo de ratos jovens, evidenciamos fibras colágenas na região da leptomeninge, com mitocôndrias, complexo de Golgi, e membranas nucleares unidas por zônulas de oclusão. No grupo de ratos adultos, identificouse fibroblasto na continuidade da dura-máter, com mitocôndrias ao seu redor, caracterizando alta atividade celular de formação de tecido fibroso (Fig.4).

Através da regressão linear estimamos uma relação matemática que descreveu a densidade de fibras elásticas, elaunínicas e oxitalânicas nas meninges encefálicas em função da faixa etária. A equação da coloração de Weigert Oxona indica que a densidade de fibras elásticas, elaunínicas e oxitalânicas são constantes, ou seja, independe da faixa etária, $p=0,785$. Diferentemente disto, a densidade de fibras elásticas da coloração de Verhoeff é de $p=0,007$ e das fibras elaunínicas da coloração de Weigert é de $p=0,003$, o que mostra que a densidade de fibras depende das faixas etárias, dado este estatisticamente significativo (Quadro 2).

\begin{tabular}{|c|c|c|c|}
\hline & $\begin{array}{l}\text { Verhoeff } \\
\left(\times 10^{-4}\right)\end{array}$ & $\begin{array}{l}\text { Weigert } \\
\left(\times 10^{-4}\right)\end{array}$ & $\begin{array}{l}\text { Weigert Oxona } \\
\qquad\left(\times 10^{-4}\right)\end{array}$ \\
\hline Neonato & $6,92 \pm 1,42$ & $6,64 \pm 0,66$ & $8,97 \pm 1,62$ \\
\hline Jovem & $6,40 \pm 1,39$ & $6,02 \pm 1,11$ & $7,34 \pm 1,41$ \\
\hline Adulto & $7,05 \pm 0,69$ & $7,47 \pm 0,85^{*}$ & $9,09 \pm 1,19$ \\
\hline Velho & $8,54 \pm 0,72^{*}$ & $8,02 \pm 0,85$ & $7,98 \pm 0,95$ \\
\hline
\end{tabular}

\section{DISCUSSÃO}

$\mathrm{Na}$ literatura consultada, poucos são os relatos sobre a organização dos envoltórios cerebrais relacionados com o crescimento do encéfalo principalmente de seus constituintes de resistência e tensão que são os sistemas de fibras colágenas e elásticas. Realizamos o estudo na região do seio sagital superior, sendo importante devido à presença das granulações aracnóides, vasos sanguíneos e por localizar feixes espessos de fibras colágenas (Thompson 1984, Conegero \& Chopard 2003).
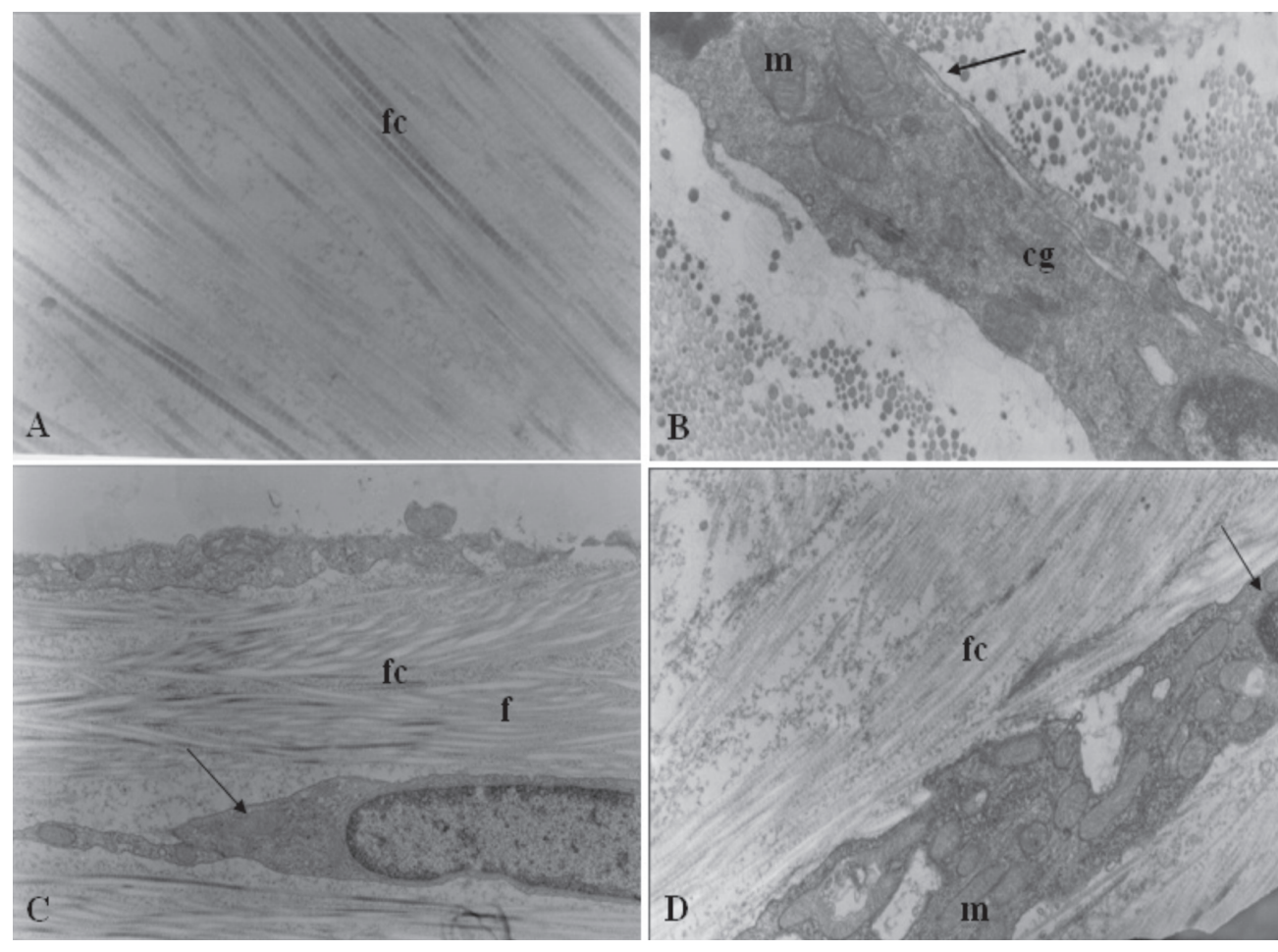

Fig.4. Micrografia eletrônica de transmissão das meninges encefálicas na região do seio sagital superior. (A) Grupo neonato, onde observamos a presença de fibras colágenas (fc) em toda extensão da paquimeninge. 60.000x. (B) Grupo jovem, evidenciando fibras colágenas na região das leptomeninges, com mitocôndrias (m), complexo de golgi (cg) e membranas nucleares unidas por zônulas de oclusão (seta). 12.930x. (C) Grupo adulto, onde observamos fibroblasto (f), envolvido por muitas mitocôndrias em toda extensão da paquimeninge (seta). As fibras colágenas (fc) estão dispostas longitudinalmente. 7.500x. (D) Grupo neonato, evidenciando a região das leptomeninges, com muitas mitocôndrias $(\mathrm{m})$, fibras colágenas (fc) e fibroblasto (seta). 10.000x. 
Todos os tecidos e órgãos apresentam um ciclo vital, que modifica sua estrutura e função em decorrência do envelhecimento, parede arterial, massa corporal, órgãos do sistema reprodutor, músculos, fígado, moléculas de colágeno e tecido elástico (Verzár 1956, 1960, Schaub 1964, Bashey et al. 1967, Zwolinski et al. 1976). Imayama \& Braverman, 1989, observaram que na pele o envelhecimento faz com que as fibras elásticas se tornem progressivamente tortuosas e com superfície irregular, as tortuosidades significariam que as fibras foram estiradas e a seguir perderam a elasticidade, determinando, como conseqüência, dobras ou rugas. Em nosso estudo, observamos modificações quantitativas nos componentes fibroelásticos das meninges, entretanto, as fibras não se apresentaram tortuosas e com superfícies irregulares, acreditando que seja devido à função de sustentação fibrosa das artérias meníngeas para o sistema nervoso central.

O sistema de fibras colágenas tem sido estudado em seus diversos aspectos de tipificação e função. Nosso trabalho analisou e quantificou o colágeno tipo I e III, pois são os dois tipos predominantes em envoltórios conjuntivos que mantêm a arquitetura e servem de proteção a determinados órgãos e vísceras. Na literatura, foi verificado que as fibras colágenas podem aumentar ou se manter estáveis, assim como diminuírem com o envelhecimento, dependendo da região ou espécie analisada (Schaub 1964, Verzár 1956, 1964, Bashey et al. 1967, Zwolinski et al. 1976, Ding et al. 1998, Hamann et al. 1998, Ferreira 2005).

No caso das meninges encefálicas, observamos que o grupo de ratos adultos apresentou uma maior área de fibras colágenas tanto de fibras do tipo I quanto do tipo III, quando comparados com os ratos dos grupos neonatos, jovens e velhos, onde estes três últimos não se diferenciam entre si, o que sugere que a maior densidade de fibras colágenas é encontrada no grupo de ratos adultos. Encontramos também que as fibras colágenas do tipo III em todos os grupos analisados ocupam uma maior área quando comparados com as fibras do tipo I. Como as fibras colágenas do tipo III atuam na manutenção da estrutura de tecidos delicados e expansíveis, o estudo mostra que as funções das meninges encefálicas não estão relacionadas apenas com a resistência a trações e tensões a que estão sujeitas o encéfalo. Mas sua função esta relacionada com a distensibilidade dos vasos meníngeos e cerebrais de acordo com a necessidade do aporte sanguíneo em diversas funções específicas regionais do tecido nervoso, dependente de sua maior ou menor atividade.

Sobre o sistema de fibras elásticas, as meninges encefálicas apresentaram variações em seu padrão de distribuição, tanto em relação à presença quanto na disposição espacial das mesmas, onde em nosso trabalho evidenciamos todas as fibras do sistema, independentes das faixas etárias. Um estudo sobre o sistema de fibras elásticas na artéria basilar de humanos relatou que o tecido elástico não se apresenta distribuído homogeneamente no interior da túnica média (Chopard 1998).

Entretanto, uma análise acerca do sistema fibroso da cápsula esplênica humana evidenciou uma homogênea distribuição de fibras elásticas no interior tecidual (Rodrigues et al. 1999). Nas meninges encefálicas dos roedores, foram encontradas poucas fibras elásticas entremeadas ao tecido colágeno em todos os grupos estudados, sendo que estas fibras não apresentam distribuição homogênea e uniforme em seu interior. Os resultados estão de acordo com os resultados de vários autores que constataram a abundância de fibras colágenas e distribuição algo randômica de fibras elásticas nas meninges (Ham 1965, Greep 1966, Lesson \& Leeson 1966, Gray 1973).

O sistema de fibras elásticas sofre um processo de desestruturação com o envelhecimento, como evidenciado na aterosclerose, no enfisema e na perda de elasticidade arterial. Foi relatado que a atividade elástica aumenta sobre os líquidos biológicos e nos tecidos ao longo do envelhecimento (Robert 1995). Os sistemas fibrosos do grupo de ratos neonatos não apresentaram diferenças significativas quando comparadas com outros grupos, demonstrando que os sistemas fibrosos nas meninges encefálicas estão presentes em todas as faixas etárias estudadas, sem alterar superfície e componentes estruturais, caracterizando que sua real função de proteção não se altera nem com o desenvolvimento nem com a atrofia cerebral. Entretanto, as fibras elásticas e elaunínicas sofreram um processo de aumento em todos os grupos e as fibras oxitalânicas apresentaram uma pequena redução progressiva desde os grupos neonatos até o grupo de ratos veIhos, o que mostra uma progressiva diminuição da resistência das meninges, constatado, inclusive, pela diminuição da densidade de fibras colágenas.

Do ponto de vista ultra-estrutural, vários trabalhos foram realizados com o intuito de descrever as estruturas meníngeas. Estudos comparativos de membranas encefálicas foram realizados entre animais de laboratório (chinchilas, coelhos, gatos, camundongos e macacos, por exemplo) (Klika 1967, Nabeshima 1975), pesquisas foram efetuadas com ratos Wistar em seus mais variados aspectos (Pease \& Schultz 1958) e meninges humanas foram estudadas (Andres 1967a, 1967b, Angelov 1990). Os aspectos ultra-estruturais das meninges encefálicas não são demonstrados no decorrer do envelhecimento, sequer em diferentes faixas etárias com foco nos constituintes de resistência e tensão - sistemas de fibras colágenas e elásticas. Os achados neste estudo revelaram a presença de muitos fibroblastos e mitocôndrias tanto na paquimeninge como na leptomeninge nos grupos de ratos neonatos $e$ adultos, indicativo de alta atividade celular e conseqüentemente, intensa formação de tecido conjuntivo, os quais estão harmônicos com os autores supracitados; evidenciaram também tais estruturas, entretanto, nas meninges dos grupos de ratos jovens e velhos, a presença de fibroblastos e mitocôndrias foram pouco observadas. Não foi possível estabelecer parâmetros diferenciais entre os grupos estudados do ponto de vista ultra-estrutural.

Este estudo mostra a importância do sistema elástico e colágeno das meninges encefálicas na região do seio 
sagital superior. Entretanto, outros poderiam revelar se outras regiões das meninges encefálicas apresentam uma estruturação dessemelhante dos componentes fibrosos em decorrência das diferentes de faixas etárias. As diferenças topográficas e estruturais das meninges espinais justificariam outro amplo estudo, visto que a disposição de cada uma delas difere das meninges encefálicas como, por exemplo, uma única camada de dura-máter, a inexistência de seios vasculares e as formações específicas da pia-máter espinais - como o filamento terminal e os ligamentos denticulados -, podendo, portanto, seus componentes de resistência e tensão apresentarem uma disposição diferenciada dos componentes fibrosos.

\section{CONCLUSÕES}

A partir da metodologia empregada e os resultados obtidos, podemos inferir que:

Em todos os grupos, a área ocupada por fibras colágenas do tipo III predominaram sobre as fibras colágenas do tipo I. Como as fibras colágenas do tipo III atuam na manutenção da estrutura de tecidos delicados e expansíveis, o estudo mostra que as funções das meninges encefálicas não estão relacionadas apenas com a resistência a trações e tensões a que estão sujeitas o encéfalo. Mas também a função relacionada com a distensibilidade dos vasos meníngeos e cerebrais de acordo com a necessidade do aporte sanguíneo em diversas funções específicas regionais do tecido nervoso.

Que o grupo de ratos adultos apresentou uma maior densidade de fibras colágenas tanto do tipo I quanto do tipo III, quando comparados com os demais grupos. A densidade linear das fibras elásticas e elaunínicas aumentou em todos os grupos e a densidade de fibras oxitalânicas apresentou redução progressiva em todos os grupos.

A microscopia eletrônica não revelou diferenças ultraestruturais entre os grupos analisados.

\section{REFERÊNCIAS}

Andres K.H. 1967a. Über die Feinstruktur der Arachnoidea und Dura mater von Mammalia. Z. Zellforschung 79(4):272-295.

Andres K.H. 1967b. Zur Feinstruktur der Arachoidalzotten bei Mammalia. Z. Zellforschung 82(3):92-109.

Angelov D.N. 1990. Ultrastructural characteristics of the cranial Dura mater-Arachnoid Interface Layer. Z. Mikrosk. Anat. Forsch. 104(6):982-990.

Bashey R.I., Torii S. \& Angrist A. 1967. Age-related collagen and elastin content of human heart valve. J. Gerontology 22:203-208.

Chopard R.P., Lucas G.A., Gerhard R. \& Lourenço M.G. 1998. A histomorphological study in age related change in the elastic fiber system of the basilar artery. Italian J. Anat. Embryol. 103(4):157-175.
Conegero C.I. \& Chopard R.P. 2003. Tridimensional architecture of the collagen element in the arachnoid granulations in humans. Arqs Neuro-Psiquiatria 61(3A):561-565.

Ding M., Dalstra J., Lindle F. \& H.I.D. I. 1998. Mechanical properties of the normal human tibial cartilagem-bone complex in relation to age. Clin. Biomechanics 13(4/5):351-358.

Ferreira T. J. 2005. Estudo histomorfométrico da artéria torácica interna em diferentes grupos etários. Dissertação de Mestrado, Instituto de Ciências Biomédicas, USP, São Paulo. 42p.

Gray H. 1973. Anatomia. 2a ed. Guanabara Koogan, Rio de Janeiro. $683 p$.

Greep R.O. 1966. Histology. $2^{\text {nd }}$ ed. McGraw-Hill Book Company, New York. 223p.

Ham A.W. 1965. Histology. $5^{\text {th }}$ ed. J.B. Lippincott Company, Philadelphia. 174p.

Hamann M.C.J., Sacks M.S. \& Malinin T.I. 1998. Quantification of the collagen fibre architecture of human cranial dura mater. J. Anat. 192: 99-106.

Imayama S. \& Braverman I.M. 1989. A hypothetical explanation the aging of skin. Am. J. Pathology 134(5):1019-1025.

Klika E. 1967. The ultrastructure of meninges in vertebrates. Medical University of South Carolina Acta 13(1):53-71.

Lesson C.R. \& Leeson T.S. 1966. Histology. W.B. Saunders Company, Philadelphia. 436p.

Nabeshima S., Reese T.S., Landis D.M.D. \& Brightman M.W. 1975. Junctions in the meninges and marginal glia. J. Comp. Neurology 164:127-170.

Pease D.C. \& Schultz R.L. 1958. Electron microscopy of rat cranial meninges. Am. J. Anatomy 102(2):301-321.

Reynolds E.S. 1963. The use of lead citrate at high pH as an electronopaque stain in electron microscopy. J. Cell Biology 17(3):208-213.

Robert L. 1995. O Envelhecimento: factos e teorias. Biblioteca Básica de Ciência e Cultura, Instituto Piaget. 74p.

Rodrigues C.J., Rodrigues Júnior A.J. \& Sacchetti J.C.L. 1999. Agerelated changes in the elastic fiber network of the human splenic capsule. Limphology 32(2):64-69.

Schaub M.C. 1964. The aging of collagen in the heart muscle. Gerontology 10(4):38-41.

Thompson D.N.P. 1984. Arachnoid villi and granulations in the rat and man: New considerations based on light and scanning electron microscopy. J. Anatomy 138(1):568.

Verzár F. 1956. Das Altern des Collagens. Helvetica Physiol. Pharmacol. Acta 14(7):207-221.

Verzár F. 1960. Nachweiss der Zunahme der Bindung von Hydroxyprolin in Collagen der Haut mit dem Alter. Gerontology 4(5):104-111.

Verzár F. 1964. Aging of the collagen fiber. Int Rev Connect Tissue Res. 2:243-300.

Watson M.L. 1958. Staining of tissue sections for electron microscopy with heavy metals. II. Applications of solutions containing lead and barium. J. Biophys. Biochem. Cytology 4(6):727-30.

Zwolinski R.J.Ç., Hamlin C.R. \& Kohn R.R. 1976. Age-related alteration in human heart collagen. Proc. Society for Experimental Biology and Medicine 152(3):362-365. 